\title{
The relation of alcohol consumption to cardiovascular risk factors and stroke. The west Birmingham stroke project
}

\author{
Roger Shinton, Gian Sagar, Gareth Beevers
}

\begin{abstract}
The disputed relation between recent alcohol consumption and stroke was examined in a community case control study. One hundred and twenty five incident first time stroke patients and 198 controls, aged 35 to 74 years, were recruited over two years from a general practice population. The age and sex adjusted relative risks for stroke by recent weekly "drinks" of alcohol were; $0-1 \cdot 0$ (reference), 1 to $14-0.57,15$ to 29-0.63, and > 29-0.99. Among the controls it was noted that non-drinkers were more likely than light/moderate drinkers (1 to 29 drinks per week) to have the following characteristics; history of obesity (p < 0.001), not a recent walker (p< $0 \cdot 05)$, and no vigorous exercise in early adulthood ( $p<0 \cdot 01)$. The apparent association of light and moderate alcohol consumption with decreased stroke risk disappeared when these variables were included in the multiple risk factor adjusted analysis; $0-1 \cdot 0,1$ to $14-0 \cdot 88,15$

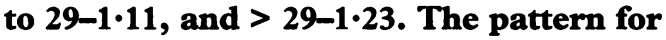
proved cerebral infarction $(n=81)$ was similar. The results of this study do not support the idea that recent heavy alcohol consumption is an important cause of either overall stroke or cerebral infarction. The association of non-drinking with a history of overweight and inactivity may explain the apparent protective effect of lighter alcohol consumption on the risks of both stroke and coronary heart disease.
\end{abstract}

$(\mathcal{F}$ Neurol Neurosurg Psychiatry 1993;56:458-462)

University of

Birmingham,

Department of

Medicine

$R$ Shinton

G Beevers

Department of Radiology, Dudley Road Hospital,

Birmingham B18 7QH

G Sagar

Correspondence to:

Dr R Shinton, University of Birmingham, Department of Geriatric Medicine, The Hayward Building, Selly Oak Hospital, Birmingham B29 6JD.

Received 30 June 1992

and in revised form

23 October 1992

Accepted 2 November 1992
There is at present no consensus on the nature of the relation between recent alcohol consumption and stroke. ${ }^{1-3}$ Reports from a series of case control studies have indicated an increased risk of stroke among recent heavy drinkers. ${ }^{4-9}$ These studies have been criticised for inappropriate selection of controls and have not always employed standardised assessment of cases and controls. ${ }^{1011}$ Two recent case control studies using standardised assessments have failed to confirm that heavy alcohol consumption is an important risk factor for stroke. ${ }^{11-13}$ These studies, however, were entirely hospital based, leaving concern about the possible influence on the results of selection factors for hospital attendance.
Several, but not all, studies have indicated that alcohol consumption is a risk factor for cerebral haemorrhage. ${ }^{14-19}$ Cohort studies have also suggested that alcohol has either a beneficial or little effect on the risks of cerebral infarction. ${ }^{14161819}$ It was, however, not always possible to confirm subtype diagnosis with CT in these studies.

Evidence has recently been presented suggesting a protective effect of light and moderate alcohol consumption on the risk of coronary heart disease. ${ }^{2021}$ The possibility that exercise may confound the relation was raised in correspondence but was surprisingly not addressed in a letter of reply from the original authors. ${ }^{22} 23$

To address the above issues a community based case control stroke study was conducted, using standardised methods of assessment of a range of variables related to lifestyle.

\section{Methods}

A community case control study was conducted involving those people registered with 11 general practice partnerships surrounding Dudley Road Hospital, Birmingham (estimated total $=101000$ )

\section{STROKE PATIENTS}

Case definition Stroke patients were assessed for inclusion by RS using the standard World Health Organisation criteria-rapidly developing clinical signs of focal and at times global (applied to patients in deep coma and to those with subarachnoid haemorrhage) loss of cerebral function, with symptoms lasting more than 24 hours or leading to death, with no apparent cause other than that of vascular origin. ${ }^{24}$ In both hospital and community stroke patients cerebral infarction was diagnosed if a CT head scan or necropsy was performed within 21 days of stroke onset and there was either no evidence of haemorrhage or a pattern of predominant infarction.

Recruitment An appointed liaison member of staff at each practice was telephoned weekly to ensure maximum recruitment. Dudley Road Hospital admission records were checked three times per week and patients with entries suggestive of possible stroke reviewed.

Inclusions and exclusions Those included were both men and women between the ages of 35 and 74 years, with their first stroke occurring between 1 October 1988 and 30 September 1990. The following characteristics excluded stroke patients from the study; a 
history of stroke (but not transient ischaemic attack), a history of mitral valvular heart disease combined with atrial fibrillation, a history of primary or metastatic cerebral neoplasm, a history of coagulation disorder or myeloproliferative disease, patients dying before assessment could be made, and those declining participation.

CONTROL SUBJECTS

Selection methods Controls were selected from age and sex groups which would broadly match the expected distribution of stroke cases (frequency matching). ${ }^{25}$ Random selection of controls was achieved in two stages. In stage one the practice from which the control was chosen was randomly selected with weighting according to practice size. In stage two controls were randomly sampled using the age-sex register as a numbered population framework. If a selected control had either moved outside the area or died a replacement was again randomly selected from the practice.

Recruitment Controls were sent an introductory letter personally signed by their general practitioner. Following contact by telephone or a visit to their home, assessment was arranged, usually at their local surgery.

Inclusions and exclusions All those on the practice registers between the ages of 35 and 74 years were eligible for inclusion. The same exclusions applied as for stroke patients.

ASSESSMENT

All participants were anthropometrically assessed and interviewed by RS using a standard structured questionnaire. Stroke patients were seen as soon as possible following the event. When disability prevented an adequate response the closest relative or friend was interviewed.

Alcohol consumption Usual weekly consumption was based on a seven day retrospective alcohol diary. "Drinks" of alcohol were divided into; (i) beer, lager, or cider, (ii) wine, (iii) aperitifs, and (iv) spirits. One drink was equivalent to half a pint of beer, lager or cider, a glass of wine, a glass of an aperitif, or a tot of spirits. A "drink" is approximately equivalent to 8 to 10 grams of absolute alcohol. The number of days on which each category of drink was consumed was multiplied by the usual daily number of drinks. The four categories were then combined to provide the weekly total: nil, not a regular weekly drinker; light, up to 14 drinks; moderate, 15 to 29 drinks; heavy, > 29 drinks. Past alcohol excess was designated by a positive response to the question: "Have you (the subject) ever been told by anyone that you (the subject) drink too much alcohol?"

General practice and Dudley Road Hospital notes were examined for the most recent record of alcohol consumption. If a record existed, an assistant, blinded to their case/control status, then classified the drinking category into four levels as outlined above.

Body fat Harpenden skinfold calipers were used to measure subscapular skinfold thickness using standard methods. ${ }^{26}$ Two records for each subject were made and the mean calculated.

Standing height was measured, where possible, by standard methods ${ }^{26}$ using a portable stadiometer. Lying height was measured in all stroke patients admitted to hospital. A simple regression equation, which related standing and lying height among stroke patients who could stand, enabled standing height to be estimated for those unable to stand. All subjects, when possible, were weighed in light clothing using portable scales with an electronic display. Body mass index was calculated as weight in kilograms/(height in metres) ${ }^{2}$. Subjects were asked; "What is the most you have ever weighed?" The response was converted into kilograms and combined with measured/derived standing height to provide maximum reported body mass index. Measured/derived standing height was combined with the maximum recorded weight, if a record was available, in the general practice or hospital notes to provide maximum recorded body mass index. Sex specific interquartile ranges among control subjects were established for all measures of body fat.

Other potential risk factors Subjects were grouped into four serial 10-year age groups for analysis. Sex and race (black, white, Asian, or other) were recorded for each individual. Questionnaire responses were used to assess social class (manual/non-manual), cigarette smoking history (never, former, current), dietary saturated fat (four levels), and perceived health status (good, average, poor). Whether or not there was a history of the following was similarly determined; vigorous exercise in the past month, walking more than 1 mile in the past month, vigorous exercise between 15 and 25 years of age, cardiac ischaemia, hypertension, diabetes mellitus, and familial stroke.

\section{STATISTICAL ANALYSIS}

An epidemiological computer software package (EGRET) was used to analyse the data. ${ }^{27}$ This program used methods described by Breslow and Day ${ }^{28}$ to calculate odds ratios (relative risks), their 95\% confidence intervals, and tests for trend in the odds ratios. Mantel-Haentzel methods were used to provide an estimate of the odds ratio after adjustment for one or two other variables. Adjustment for several variables was made by use of the multiple logistic regression model. Regression models were all fitted using exposure levels of a given risk factor as discrete (factored) variables.

\section{Results}

One hundred and thirty seven stroke patients with their first event were identified, 12 were excluded (seven died before assessment), leaving 125 cases for analysis (response rate $100 \%$ ). Almost half of the stroke patients were initially managed at a venue other than Dudley Road Hospital, 34\% remaining at 
Figure 1 Relation between alcohol consumption and stroke. Multiple risk factor adjusted results based on 124 cases and 196 controls the logistic models were; age group, sex, race [black/non-black], cigarette smoking status [never, former, and current], quartile of maximum reported body mass index, quartile of thickness, dietary saturated fat [four levels], recent vigorous exercise, recent walking, and vigorous exercise aged 15 to 25 years). Bars indicate $95 \%$ confidence intervals. (covariables included in subscapular skinfold

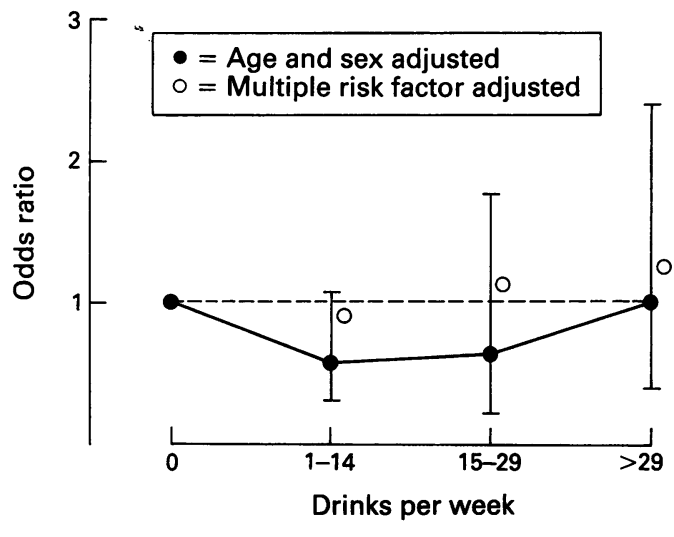

home. Cerebral infarction was diagnosed in 81 patients, intracerebral haemorrhage in five, and subarachnoid haemorrhage in four. Assessment was within 7 days of stroke onset for $68 \%$ and within 14 days for $90 \%$ of cases.

Of the 220 controls selected and contacted, 13 were excluded because of a history of stroke (10) or warfarin treatment (three), leaving 207 eligible subjects of whom 198 $(96 \%)$ agreed to participate. The median age of cases was 66 years and of controls 63 years.

\section{REPRODUCIBILITY OF REPORTED ALCOHOL CONSUMPTION}

Comparison of questionnaire responses and previous medical records in both cases ( $\mathrm{n}=$ 76) and controls $(n=86)$ revealed alcohol consumption was within the same category on both assessments in $62 \%$ of cases/controls combined. Cases tended to be more consistent than controls in reporting heavy alcohol consumption.

ALCOHOL AND POTENTIAL CONFOUNDING CHARACTERISTICS

Among the control population cigarette

Table Relation between level of alcohol consumption and stroke by sex, age group, and history of cardiovascular disease

\begin{tabular}{|c|c|c|c|c|}
\hline & \multicolumn{4}{|c|}{ Odds ratio ( $95 \%$ confidence interval) } \\
\hline & \multicolumn{4}{|c|}{ Drinks per week } \\
\hline & 0 & $1-14$ & $15-29$ & $>29$ \\
\hline $\begin{array}{l}\text { Age adjusted } \\
\text { [cases/controls] }\end{array}$ & $\begin{array}{l}(1 \cdot 0) \\
{[34 / 35]}\end{array}$ & $\begin{array}{l}\text { Men } \\
0 \cdot 46 \\
(0 \cdot 19-1 \cdot 11) \\
{[13 / 29]}\end{array}$ & $\begin{array}{l}0.71 \\
(0 \cdot 24-2 \cdot 08) \\
{[9 / 13]}\end{array}$ & $\begin{array}{l}0 \cdot 83 \\
(0 \cdot 35-1 \cdot 9) \\
{[17 / 21]}\end{array}$ \\
\hline $\begin{array}{l}\text { Age adjusted } \\
\text { [cases/controls] }\end{array}$ & $\begin{array}{l}(1 \cdot 0) \\
{[38 / 60]}\end{array}$ & $\begin{array}{l}\text { Women } \\
0 \cdot 70 \\
(0 \cdot 29-1 \cdot 68) \\
{[13 / 33]}\end{array}$ & $\overline{[0 / 5]}$ & $\overline{[1 / 2]}$ \\
\hline $\begin{array}{l}\text { Sex adjusted } \\
\text { [cases/controls] }\end{array}$ & $\begin{array}{l}(1 \cdot 0) \\
{[15 / 19]}\end{array}$ & $\begin{array}{l}\text { Age } 35 \text { to } 64 \\
0 \cdot 63 \\
(0 \cdot 24-1 \cdot 63) \\
{[21 / 55]}\end{array}$ & $\begin{array}{l}0 \cdot 23 \\
(0 \cdot 04-1 \cdot 23) \\
{[3 / 12]}\end{array}$ & $\begin{array}{l}0.56 \\
(0 \cdot 17-1 \cdot 66) \\
{[11 / 20]}\end{array}$ \\
\hline $\begin{array}{l}\text { Sex adjusted } \\
\text { [cases/controls] }\end{array}$ & $\begin{array}{l}(1 \cdot 0) \\
{[49 / 54]}\end{array}$ & $\begin{array}{l}\text { Age } 65 \text { to } 74 \\
0 \cdot 50 \\
(0 \cdot 22-1 \cdot 15) \\
{[13 / 29]}\end{array}$ & $\begin{array}{l}1 \cdot 10 \\
(0 \cdot 27-4 \cdot 49) \\
{[6 / 6]}\end{array}$ & $\begin{array}{l}2 \cdot 85 \\
(0 \cdot 54-16 \cdot 6) \\
{[7 / 3]}\end{array}$ \\
\hline $\begin{array}{l}\text { Age/sex } \\
\text { adjusted } \\
\text { [cases/controls] }\end{array}$ & $\begin{array}{l}\text { No card } \\
(1 \cdot 0) \\
{[38 / 67]}\end{array}$ & $\begin{array}{l}\text { ar disease histo } \\
0 \cdot 29 \\
(0 \cdot 09-0 \cdot 76) \\
{[6 / 42]}\end{array}$ & $\begin{array}{l}0.97 \\
(0 \cdot 22-4 \cdot 27) \\
{[5 / 11]}\end{array}$ & $\begin{array}{l}0 \cdot 75 \\
(0 \cdot 21-2 \cdot 52) \\
{[8 / 19]}\end{array}$ \\
\hline $\begin{array}{l}\text { Age/sex } \\
\text { adjusted } \\
\text { [cases/controls] }\end{array}$ & $\begin{array}{l}\text { History } \\
(1 \cdot 0) \\
{[34 / 28]}\end{array}$ & $\begin{array}{l}\text { vascular diseas } \\
0 \cdot 76 \\
(0 \cdot 43-2 \cdot 86) \\
{[20 / 20]}\end{array}$ & $\begin{array}{l}0 \cdot 41 \\
(0 \cdot 07-1 \cdot 89) \\
{[4 / 7]}\end{array}$ & $\begin{array}{l}1 \cdot 47 \\
(0 \cdot 47-17 \cdot 8) \\
{[10 / 4]}\end{array}$ \\
\hline
\end{tabular}

smoking was positively associated with alcohol consumption (trend in odds ratio $\mathrm{p}<$ $0.001)$. Non-drinkers, compared with light and moderate drinkers, tended to be (i) in the upper quartile of maximum reported $(\mathrm{p}<$ $0.001)$ and maximum recorded $(p<0.01)$ body mass index, (ii) not recent walkers ( $p<$ 0.05 ), and (iii) not vigorously active aged 15 to 25 years $(p<0.01)$. These trends were seen in both sexes. Similar (non-significant) trends were seen for body mass index, subscapular skinfold, and recent vigorous exercise. A non-significant association of heavy drinking and high dietary saturated fat was also noted.

\section{ALCOHOL CONSUMPTION AND STROKE}

The age and sex adjusted odds ratios relating alcohol and overall stroke suggest little adverse effect of heavy drinking but a protective effect of light/moderate alcohol consumption (fig 1). To assess any influence of possible confounding variables on the relation, adjusted odds ratios were computed for all the variables listed in the methods. None of these adjustments had an appreciable effect on the odds ratio for heavy drinking. The apparent protective effect of light/moderate drinking was attenuated by adjustment for age group, measures of overweight, and all the indicators of inactivity. After multiple adjustment of the odds ratios by potential risk factors related to alcohol, no effect of any level of alcohol consumption on stroke risk could be detected (fig 1 ). When the relation was analysed separately by sex, similar patterns were seen (table). Multiple risk factor adjustment produced an attenuation of the apparent protective effect of light drinking in both men and women (results not presented).

As previous workers have reported an adverse effect of heavy alcohol consumption in both younger stroke patients ${ }^{4} 6$ and among those without a history of cardiovascular disease $^{29}$ the alcohol/stroke relation was examined separately by age group and in those with and without a history of hypertension or ischaemic heart disease (table). In neither assessment was any consistent difference noted.

The age and sex adjusted odds ratios of alcohol consumption during the 48 hours before either stroke onset or the interview (controls) were not perceptibly different from that seen with the seven day alcohol history; $0-1 \cdot 0,1-4$ drinks $-0.48,5-8$ drinks -0.95 , and $>8$ drinks $-1 \cdot 20$.

A history of excessive alcohol consumption appears to have little effect on the risk of stroke; age and sex adjusted odds ratio- 0.83 (95\% confidence interval 0.33 to 1.35 ).

To examine the possibility that surrogate responses could be distorting the results, an analysis was performed which included only those cases $(n=95)$ and controls $(n=196)$ who answered the questionnaire themselves. The age and sex adjusted odds ratios for weekly alcohol consumption were similar to the full analysis; nil- 1.0 , light -0.64 , moderate -0.61 , and heavy -0.87 . 
Figure 2 Relation between alcohol consumption and cerebral infarction. Based on 80 cases and 196 controls (covariables included in the logistic models were; age group, sex, race cigarette smoking status [never, former, and current], quartile of maximum reported body mass index, quartile of subscapular skinfold thickness, dietary saturated fat [four levels], recent vigorous exercise, recent walking and vigorous exercise aged 15 to 25 years). Bars indicate $95 \%$ confidence intervals.

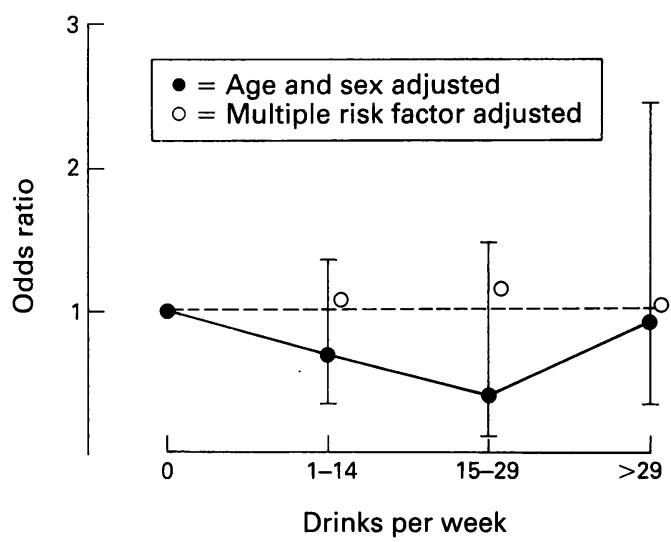

Because stroke patients seemed to be reporting heavy alcohol consumption with a similar frequency to controls, a check was made towards the end of the study that heavy drinking stroke cases were not being misclassified as moderate/light/non-drinkers. In a sequential series of 18 stroke patients a blood ethanol level was measured at presentation (West Midlands Toxicology Laboratory). Only two of the 18 revealed any ethanol in the blood-in both patients but no others was a 24 hour history of substantial alcohol consumption reported ( $>$ six drinks).

Results for proved cerebral infarction ( $\mathrm{n}=$ 81) were similar to those for all stroke cases (fig 2).

\section{Discussion}

The results of this project do not support the hypothesis that recent regular heavy alcohol consumption is an important risk factor for either stroke as a whole or cerebral infarction in particular. Modest effects of alcohol on stroke risk, either beneficial or adverse, are not excluded by these observations. This finding is consistent with the effect of alcohol observed with cardiovascular risk in cohort studies. ${ }^{30-32}$ The results do not, however, exclude the possibility that heavy alcohol consumption can precipitate cerebral haemorrhage as there were only nine patients studied known to have this subtype. They also do not exclude the possibility that on rare occasions binge drinking can precipitate stroke, although none was encountered in this study. There is no suggestion, furthermore, that a history of excessive alcohol consumption carries an increased risk of stroke.

There may be several explanations for the absence of an adverse effect of heavy drinking on stroke, despite the broad consensus that regular heavy alcohol consumption does elevate blood pressure. Estimates of the effect of alcohol on blood pressure indicate that a $5-10 \mathrm{~mm} \mathrm{Hg}$ rise is the most that would be expected. The consequent small increases in risk may be epidemiologically imperceptible, particularly with complex interrelationships between potentially important risk factors clouding any associations. A second possibility is that alcohol may adversely affect blood pressure but may have some other protective effect on the development of vascular disease (for example on blood lipids) which produces no net effect.

There are reasons to believe that the results of this case control study are easier to interpret than others in which an association between stroke and heavy drinking was found. The same structured questionnaire and interviewer for both stroke patients and controls was not reported as a feature of the latter studies. ${ }^{4-9}$ Any tendency arising from different interview styles in these studies could have introduced an important recall bias, perhaps tending to extract a more accurate, and quantitatively greater, alcohol history from stroke patients. When standardised questionnaires and interviewers were used in two recently reported hospital case control studies, no adverse effect of heavy drinking on cerebral infarction was seen. ${ }^{12} 13$

It is unlikely that selection biases could have hidden a substantial adverse effect of alcohol as the study was community based. Examination of the hospital versus home managed stroke patients in this study revealed somewhat higher prevalences of heavy drinking among hospital cases-16\% versus $12 \%$ respectively. This study also suggests selection bias can be a substantial problem among controls. In the previous Dudley Road Hospital study $4 \%$ of hospital controls consumed $>29$ drinks per week, ${ }^{7}$ whereas the prevalence was $12 \%$ among community controls in the present study.

It is inevitable that some stroke cases arising in the study population will not have been detected. A group of patients with mild neurological dysfunction will have either not been recognised by the patient or not have presented to any medical practitioner. Several observations, however, provide some reassurance that the vast majority of stroke patients presenting to medical practitioners were recruited; the overall incidence rate was similar to that in other studies, ${ }^{25}$ the proportion of patients managed at home (34\%) was around that expected in this age group, ${ }^{33}$ and all practices and almost all general practitioners notified patients.

None of the assessments of possible recall bias reported in the results indicated that this was likely to obscure an adverse effect of alcohol. The tendency appeared, if anything, for stroke patients to be more frank about their heavy drinking.

The association of light drinkers with a decreased risk of stroke is consistent with many other studies of both cardiovascular disease and stroke. ${ }^{71618-213032}$ Dispute continues as to whether this is due to a protective effect of alcohol or to the influence of confounding variables. The disappearance of the protective effect of alcohol seen in this study, when adjustment for other risk factors was made, lends weight to the argument that the association is a result of confounding.

Strong associations with alcohol consumption were seen among the controls between current but particularly past excessive body fat and inactivity. These variables have not been assessed in some recent epidemiological 
studies which have indicated a protective effect of light drinking for coronary heart disease. ${ }^{2021}$ The observed associations in this population indicate that both lifelong exercise and body fat patterns are likely to confound any relation of alcohol consumption with cardiovascular disease. Studies which fail to address these interrelationships would appear hard to interpret.

We are indebted to the patients, liason staff, and partners in the 11 participating general practices: Bearwood Road Surgery, Smethwick Dr OO Dervish, Dr SH Dervish, Dr JME Hyde, Dr Y Iqbal, Dr H Shire, Mrs Diane Adams; Birchfield Medical Centre Dr ME Clarkson, Dr IG Cox, Dr LA Pike, Dr A Thake, Mrs Olive Woollas; Cape Hill Medical Centre Dr DI Child, Dr A Gaston, Dr M Hale, Dr RA Loveless, Dr DG Towers, Dr IL Wearn, Mrs Ann Anderson; Church Lane Towers, Dr J Wearn, Mrs Ann Anderson; Church Lane Massey, Dr PMO Massey, Mrs Lynn Craig; Hamstead Road Massey, Dr PMO Massey, Mrs Lynn Craig; Hamstead Road Surgery, Handsworth/Great Barr Dr G Atkins, Dr SK Bhalla, Dr DK Majevadia, Dr B Watson, Ms Kamla Mack; Lee Bank
Health Centre Dr B Colston, Dr I Fletcher, Dr JA Paris, Dr DR Morgan, Mrs Catherine Bakewell; Newtown Health Centre Dr EG Carolan, Dr D Haas, Dr PK Misra, Dr S Mukerjee, Dr E O'Brien, Dr R Orsborn, Dr S Ray, Mrs Patricia Lazenby, Mrs Sheila Lamb; Plough and Harrow Medical Centre, Ladywood Dr PHR Bryson, Dr M Forrest, Dr MJ Laird, Dr AH Macdonald, Dr LL Ostrowski, Dr R Takes, Ms Christine Lynch; Sherwood House Surgery, Bearwood Dr AJG Campbell, Dr FE Campbell, Dr DH Johnson, Dr J Kay, Dr MJ Mortimer, Dr RM Palmer, Dr P Preston, Mrs Jo Walker Tower Hill Health Centre Dr SS Bath, Dr DK Calderwood, Dr VS Calderwood, Dr DK Nandi, Mrs Deborah Bond; Victoria Health Centre, Smethwick Dr AP Joseph, Dr FA Khan, Dr DA

George.

We are grateful to the following for their advice; Professor MJS Langman, Dr IJ Perry, Professor GA Rose, Dr R Skinner.

The project was funded by the Wellcome Trust.

1 Dyken ML, Wolf PA, Barnett HJM, et al. Risk factors in stroke: a statement for physicians by the subcommittee on risk factors and stroke of the Stroke Council. Stroke 1984;15:1105-11.

2 Camargo CA. Moderate alcohol consumption and stroke: the epidemiologic evidence. Stroke 1989;20:1611-26.

3 Royal College of Physicians Working Party. Stroketowards better management. London: Royal College of Physicians, 1989

4 Hillbom $M$, Kaste $M$. Does ethanol intoxication promote brain infarction in young adults? Lancet 1978;ii:1181-3.

5 Hillbom M, Kaste M. Alcohol intoxication: a risk factor for primary subarachnoid haemorrhage. Neurology 1982;32:706-11.

6 Taylor JR, Combs-Orme T. Alcohol and strokes in young adults. Am f Psychiatry 1985;142:116-8.

7 Gill JS, Zezulka AV, Shipley MJ, Gill SK, Beevers DG. Stroke and alcohol consumption. N Engl f Med 1986; 315:1041-6.

8 Gill JS, Shipley MJ, Hornby RH, Gill SK, Beevers DG. A community case-control study of alcohol consumption in stroke. Int $f$ Epidemiol 1988;17:542-7.

9 Syrianen J, Valtonen VV, Iivanainen $M$, Kaste $M$, Huttunen JK. Preceding infection as an important risk factor for ischaemic brain infarction in young and middle aged patients. $B M F$ 1988;296:1156-60.

10 Kiefe C, Freiman J. Stroke and alcohol consumption. $N$ Engl F Med 1987;316:1214.

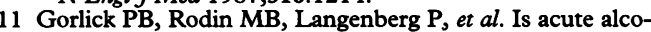
hol ingestion a risk factor for ischaemic stroke? Stroke 1987; 18:359-64.

12 Gorlick PB, Rodin MB, Langenberg P, Hier DB, Costigan J. Weekly alcohol consumption, cigarette smoking, and the risk of ischaemic stroke: results of a case-control study at three urban medical centers in Chicago, Illinois. Neurology 1989;39:339-43.

13 Henrich JB, Horwitz RI. Evidence against the association between alcohol use and ischaemic stroke risk. Arch Intern Med 1989;149:1413-6.

14 Tanaka $H$, Veda $Y$, Hayashi $M$, et al. Risk factors for cerebral haemorrhage and cerebral infarction in a Japanese rural community. Stroke 1982;13:62-73.

15 Sacco RL, Wolf PA, Bharucha NE, et al. Sub-arachnoid and intracerebral haemorrhage: natural history, prognosis and precursive factors in the Farmingham study. Neurology 1984;34:847-54.

16 Donahue RP, Abbott RD, Reed DM, Yano K. Alcohol and haemorrhagic stroke: the Honolulu Heart Program. भAMA 1986;255:2311-4.

17 Calandre L, Arnal C, Ortega JF, et al. Risk factors for spontaneous cerebral hematomas. Case-control study. Stroke 1986;17:1126-8.

18 Klatsky AL, Armstrong MA, Friedman GD. Alcohol use and subsequent cerebrovascular disease hospitalisations. and subsequent cereb.

19 Stampfer MJ, Colditz GA, Willett WC, Speizer FE, Hennekens $\mathrm{CH}$. A prospective study of moderate alcohol consumption and the risk of coronary disease and stroke in women. N Engl F Med 1988;319:267-73.

20 Jackson R, Scragg R, Beaglehole R. Alcohol consumption and risk of coronary heart disease. $B M F$ 1991;303: 211-6.

21 Rimm EB, Giovannucci EL, Willett WC, et al. Prospective study of alcohol consumption and risk of coronary disease in men. Lancet 1991;338:464-8.

22 Orlander JD. Alcohol and mortality. Lancet 1991;338: 1073.

23 Rimm EB, Giovannucci E, Willett WC, et al. Alcohol and mortality. Lancet 1991;338:1073-4.

24 World Health Organisation. Cerebrovascular diseasesprevention, treatment and rehabilitation. Technical report series no 469. WHO: Geneva, 1971.

25 Oxfordshire Community Stroke Project. Incidence of stroke in Oxfordshire: first year's experience of a community stroke register. $B M \mathcal{M}$ 1983;287:713-7.

26 Weiner JS, Lourie JA. Human biology: a guide to field methods. IBP Handbook No. 9. Oxford: Blackwell Scientific Publications, 1969.

27 EGRET. Seattle: Statistics and epidemiology research corporation, 1990.

28 Breslow NE, Day NE. Statistical methods in cancer research. Volume I-The analysis of case-control studies. Lyon: International Agency for Research on Cancer, 1980.

29 Shaper AG, Phillips AN, Pocock SJ, Walker M Macfarlane PW. Risk factors for stroke in middle-aged Macfarlane PW. Risk factors for stroke

30 Marmot MG, Rose G, Shipley MJ, Thomas BJ. Alcohol and mortality; a u-shaped curve. Lancet 1981;i:580-3.

31 Gordon T, Kannel WB. Drinking habits and cardiovascular disease: the Framingham study. Am Heart $\mathcal{f}$ 1983;105:667-73.

32 Shaper AG, Wannamethee G, Walker M. Alcohol and mortality in British men: explaining the $u$-shaped curve. Lancet 1988;ii:1267-73.

33 Bamford J, Sandercock P, Warlow C, Gray M. Why are patients with acute stroke admitted to hospital? The experience of the Oxfordshire Community Stroke Project. BMf 1986;292:1369-72. 